\title{
Genetic Sub-Region Sequence
}

National Cancer Institute

\section{Source}

National Cancer Institute. Genetic Sub-Region Sequence. NCI Thesaurus. Code C135485.

The determination of the sequence of nucleotide residues along a genetic sub-region of interest. 